\title{
In a tight spot: ARE-mRNAs at processing bodies
}

\author{
Georg Stoecklin ${ }^{1}$ and Paul Anderson ${ }^{2,3}$ \\ ${ }^{1}$ German Cancer Research Center, 69120 Heidelberg, Germany; ${ }^{2}$ Division of Rheumatology, Immunology, and Allergy, \\ Brigham and Women's Hospital, Harvard Medical School, Boston, Massachusetts 02115, USA
}

Compartimentalization of proteins and nucleic acids within nuclear and cytoplasmic domains is essential for many cellular functions (Spector 2006). Although biochemical analysis of cellular lysates has provided important information about the processes of mRNA translation and decay, recent results showing that these events occur at discrete cytoplasmic RNA granules (Anderson and Kedersha 2006) makes it essential that we understand the contribution of subcellular localization to these basic mechanisms. In this issue of Genes \& Development, Franks and Lykke-Andersen (2007) describe the importance of cytoplasmic processing bodies (PBs) in regulating the translation and decay of a class of mRNAs bearing an adenine/uridine-rich destabilizing element. Their studies provide important new insights into the link between mRNA translation and decay by revealing the role that RNA granules play in these processes.

\section{As and Us mark short-lived mRNAs}

In 1986, a highly conserved sequence motif composed of adenosine and uridine residues caught the eye of a group of scientists who were analyzing newly cloned cytokine cDNAs. The adenine/uridine-rich elements (AREs) found in the 3' untranslated regions (UTRs) of these transcripts were predicted to regulate some aspect of mRNA metabolism (Caput et al. 1986). In that same year, an ARE was shown to cause the rapid degradation of mRNA encoding granulocyte macrophage-colony-stimulating factor (GM-CSF) (Shaw and Kamen 1986). In ensuing years, it has become clear that ARE-mediated decay (AMD) is a common mechanism that may regulate the expression of up to $5 \%-8 \%$ of all mRNAs (Bakheet et al. 2006). Several groups identified proteins that bind to AREs, but a breakthrough was made unexpectedly by scientists studying a putative transcription factor known as tristetraprolin (TTP or ZFP36). Mutant mice lacking TTP showed signs of severe generalized inflammation, a phenotype that was caused by overproduction of tumor necrosis factor- $\alpha$ (TNF $\alpha$ ) (Carballo et al. 1998). Surprisingly, the transcription rate of $\mathrm{TNF} \alpha$ was normal in these mice, yet TNF $\alpha$ mRNA was found to be stabilized. Indeed, TTP turned out to be an RNA-binding protein

${ }^{3}$ Corresponding author.

E-MAIL panderson@rics.bwh.harvard.edu; FAX (617) 525-1310.

Article is online at http://www.genesdev.org/cgi/doi/10.1101/gad.1538807. that recognizes AREs and promotes rapid decay of AREcontaining transcripts. Two related proteins, butyrate response factor-1 (BRF1 or ZFP36L1) and BRF2 (ZFP36L2), also induce AMD (Lai et al. 2000; Stoecklin et al. 2002). It is important to note that the ARE is a very heterogeneous element, and that other ARE-binding proteins such as KSRP and AUF1 also promote AMD by targeting a distinct type of ARE (Barreau et al. 2005; Stoecklin and Anderson 2006).

\section{PBs are sites of mRNA decay and translational repression}

PBs were initially discovered as foci at which the major cytoplasmic 5'-3' exoribonuclease Xrn1 is concentrated (Bashkirov et al. 1997). It later became clear that many other enzymes involved in the breakdown of RNA are also contained in $\mathrm{PBs}$, including deadenylases and the decapping enzyme Dcp2 together with associated activators (Eulalio et al. 2007; Garneau et al. 2007). This led to the hypothesis that PBs might be actual sites of mRNA decay. In Saccharomyces cerevisiae, mRNA decay intermediates are detected in PBs, where they massively accumulate in strains with reduced Xrn1 or decapping activity (Sheth and Parker 2003). In mammalian cells, mRNAs also accumulate in PBs after knockdown of Xrn1 (Cougot et al. 2004). These experiments suggest that mRNAs undergo $5^{\prime}-3^{\prime}$ decay in PBs. It is important to keep in mind, however, that an alternative decay pathway can degrade mRNA from the $3^{\prime}$ end via a complex of $3^{\prime}-5^{\prime}$ exonucleases termed the exosome (Shen and Kiledjian 2006). Exosome components are not known to be found in PBs, although they are concentrated at cytopasmic foci in Drosophila cells (Graham et al. 2006). It is therefore likely that mRNA decay can also occur in the cytoplasm outside of PBs.

In addition to mRNA decay factors, several proteins involved in repressing translation are also concentrated in PBs (Pillai et al. 2006; Eulalio et al. 2007). Examples include Dhh1/Rck, a helicase implicated in the process of stress-induced translational silencing (Coller and Parker 2005), and components of the RNA-induced silencing complex (e.g., argonautes, GW182) that mediate microRNA (miRNA)-induced translational silencing (Pillai et al. 2006; Eulalio et al. 2007). More importantly, the specific mRNA that undergoes translational repression relocalizes to PBs (for review, see Pillai et al. 2006; 
Eulalio et al. 2007) and derepression (i.e., reactivation of translation) causes it to exit PBs again (Brengues et al. 2005; Liu et al. 2005; Pillai et al. 2005; Bhattacharyya et al. 2006). These experiments have provided compelling evidence that PBs serve as a distinct compartment that harbors translationally repressed mRNAs.

\section{Connecting the dots}

Building on this background, Franks and LykkeAndersen (2007) show that ARE-containing mRNAs are specifically targeted to PBs. Together with the observation that TTP/BRF proteins are localized in PBs (Kedersha et al. 2005), this result suggests that TTP induces AMD by bringing ARE-mRNAs into contact with the decay factors residing within PBs. Figure 1 shows the striking colocalization of recombinant TTP (Fig. 1A), BRF1 (Fig. 1B), and BRF2 (Fig. 1C) with endogenous Dcpla (a component of the decapping complex) at PBs in COS7 cells. Although PBs contain the $5^{\prime}-3^{\prime}$ exonuclease $\mathrm{Xrn} 1$, the question of whether AMD occurs in the $3^{\prime}-5^{\prime}$ or in the $5^{\prime}-3^{\prime}$ direction has been a controversial issue. A role for $3^{\prime}-5^{\prime}$ decay is supported by (1) in vitro decay assays, (2) the interaction of destabilizing ARE-binding proteins (TTP, BRF1, and KSRP) with the exosome, and (3) the finding that the exosome component Pm-Scl 75 directly binds to AREs (Chen et al. 2001; Mukherjee et al. 2002; Lykke-Andersen and Wagner 2005). A role for 5 ' -3 ' decay is supported by (1) activation of decapping by the the ARE in vitro; (2) the interaction of TTP and BRF1 with the decapping complex; (3) the localization of TTP, BRF1, and BRF2 in PBs (see Fig. 1); and (4) the observation that depletion of Xrn1 and Lsm1 (an activator of decapping) in human cells inhibits AMD to a larger extent than depletion of exosome components (Gao et al. 2001; Kedersha et al. 2005; Lykke-Andersen and Wagner 2005; Stoecklin et al. 2006). The novel finding that AREmRNAs are specifically targeted to PBs is a further indication that 5 ' -3 ' degradation may be the primary AMD pathway. Moreover, Franks and Lykke-Andersen (2007) demonstrate that tethering of either TTP or BRF1 to a reporter mRNA lacking an ARE is sufficient to direct the mRNA toward PBs. Since tethering of TTP/BRF1 is also sufficient to induce decay of the mRNA (LykkeAndersen and Wagner 2005), these findings shed new light on the mechanism by which TTP/BRF proteins induce AMD. It appears that upon binding their target mRNAs, TTP/BRF1 either deliver their associated mRNA to pre-existing $\mathrm{PBs}$ or recruit the $5^{\prime}-3^{\prime}$ decay machinery to the mRNA to effectively nucleate PB assembly. The latter possibilty may explain why the number and size of PBs is highly variable and influenced by environmental conditions (see below).

Franks and Lykke-Andersen (2007) also provide insight into the mechanisms by which mRNAs that are released from polysomes become sequestered in PBs. They show that reporter transcripts whose translation is prevented by the introduction of a hairpin in the 5'UTR are excluded from polysomes. These transcripts do not appear in PBs unless they possess elements that recruit TTP or

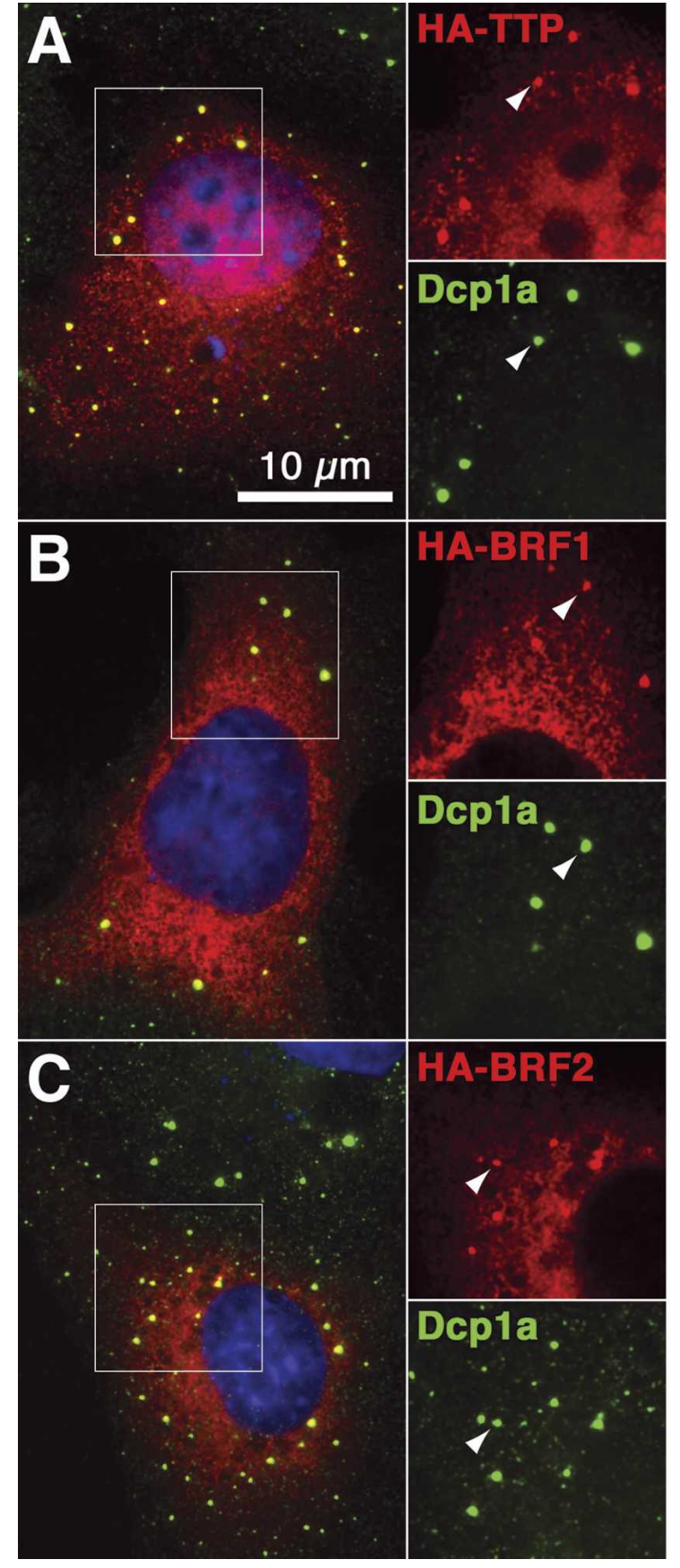

Figure 1. ARE-binding proteins of the $\mathrm{CCCH}$ zinc finger family colocalize with processing bodies. The localization of HA-tagged TTP $(A)$, HA-tagged BRF1 $(B)$, and HA-tagged BRF2 $(C)$ is shown by immunofluorescence microscopy. COS7 cells were transiently transfected with pcDNA3 vectors expressing the corresponding cDNAs, reseeded onto glass coverslips, and fixed after $2 \mathrm{~d}$. Cells were stained in red with a mouse monoclonal HA antibody (HA.11, Covance) and counterstained in green for processing bodies with a rabbit polyclonal Dcpla antibody (kindly provided by Jens LykkeAndersen, University of Colorado, Boulder, CO). Nuclei were stained with Hoechst dye (blue). The enlarged inserts separately depict the HA and Dcpla stainings; P-bodies are marked by arrows. 
BRF1. Thus, polysome disassembly is not sufficient to direct mRNA to PBs. The high efficiency by which AREmRNAs are targeted to PBs is not enhanced by the hairpin, suggesting that the ARE has a separate role in promoting translational silencing and polysome disassembly. In contrast, the lower efficiency by which TTP/ BRF1-tethered mRNA is targeted to PBs is enhanced by the hairpin. This indicates that the function of TTP/BRF proteins is to deliver the stalled mRNA to the decay machinery, but not to suppress translation of the mRNA. By the same token, this would indicate that other ARE-binding proteins function as repressors of translation (e.g., TIA-1 and TIAR) (Piecyk et al. 2000) and thereby facilitate TTP/BRF-mediated delivery to PBs.

The role of deadenylation in the assembly of PBs and the degradation of ARE-mRNAs remains to be determined. Yeast strains deficient in Ccr4, an essential component of the major deadenylation pathway, are deficient in PBs (Sheth and Parker 2003). As deadenylation is an essential first step in the general mRNA decay pathway (Beelman and Parker 1995), Ccr4-deficient cells may be unable to efficiently disassemble polysomes. Reduced levels of untranslated mRNA may result in reduced numbers of PBs in these cells. TTP has been reported to interact with cytoplasmic deadenylases and promote deadenylation of ARE-mRNAs, suggesting that it may initiate the decay process by promoting mRNA deadenylation (Lai et al. 1999, 2003). PBs do not contain PABP (Kedersha et al. 2005), suggesting that their mRNA cargo is mostly deadenylated. Since PBs contain some Ccr4 (Sheth and Parker 2003), it remains to be determined whether deadenylation occurs before or after mRNAs arrive at the PB.

\section{PBs come and PBs go}

PBs are highly dynamic in several ways. First, PBs zig-zag through the cytoplasm in what apprears to be a nondirected manner (Kedersha et al. 2005). Second, PBs enter frequent but transient contacts with stress granules, a distinct compartment of translationally stalled yet polyadenylated mRNAs that aggregate in stressed cells (Kedersha et al. 2005). Third, PBs dramatically increase in size and number in response to the release of mRNAs from polysomes, as can be seen upon treatment with the translation inhibitor puromycin. This is also observed after exposing both yeast and mammalian cells to different forms of stress, which causes a general arrest of translation that is accompanied by the appearance of new PBs (Sheth and Parker 2003; Kedersha et al. 2005). Conversly, inhibition of polysome disassembly by cycloheximide results in the loss of PBs (Brengues et al. 2005). The absence of untranslated mRNA effectively turns off the spigot for PB assembly. Under these conditions, the hairpin-containing ARE reporter described above is not found in PBs unless the decay machinery is crippled by depletion of Dcp1, and then only in a minority of cells. This result suggests that $\mathrm{TTP} / \mathrm{BRF}$ proteins may recruit the decay machinery and degrade ARE-mRNAs outside of visible PBs. Confirmation of this hypothesis will require a demonstration that the hairpin-containing ARE reporter is rapidly degraded in cells treated with cycloheximide. Interestingly, interfering with miRNA biogenesis creates a phenotype that is similar to that produced by cycloheximide; e.g., reduced numbers of PBs are a possible consequence of the reduced availability of translationally repressed mRNAs (Pauley et al. 2006). In contrast, PBs increase in size and number when mRNA decay is inhibited; e.g., after reducing decapping or Xrn1 activity (Sheth and Parker 2003; Cougot et al. 2004). Thus, the assembly and disassembly of PBs appears to depend on the flux of RNA in and out of PBs. This interpretation would further suggest that PB-related processes (translational repression and mRNA decayl may also occur at submicroscopic, nonvisible equivalents of PBs. Indeed it has been shown that visible $\mathrm{PBs}$ are dispensable for AMD, since knockdown of GW182 (a protein required for miRNA-induced translational repression) effectively abolishes PBs, but does not inhibit AMD (Stoecklin et al. 2006). Vice versa, knockdown of Lsm1 (an activator of decapping required for AMD) also abolishes PBs, but does not affect miRNA function (Chu and Rana 2006). Following such a dynamic model of PB assembly, large (i.e., visible) and numerous PBs would reflect a state in which the influx into PBs exceeds the efflux rate, leading to an accumulation of translationally stalled mRNAs. Some of these mRNAs will be able to exit PBs and reenter the translation cycle, whereas others have to wait for decay. Thus, the PB may be thought of as a capacitor that sequesters mRNA from the translational machinery when the amount of mRNA targeted for degradation exceeds the capacity of the decay machinery.

\section{Death row: pardons and executions}

Franks and Lykke-Andersen (2007) present yet another example of the important link between mRNA translation and decay. It has long been known that translational silencing can deliver an mRNA to the decay pathway (Schwartz and Parker 1999). When execution is not immediate, however, the PB can serve as a death row where RNA is held awaiting execution. In the case of ARE transcripts, TTP and BRF proteins are tickets to death row. In contrast, the ARE-binding protein $\mathrm{HuR}$ can provide a death row pardon (Bhattacharyya et al. 2006), allowing mRNA to escape the $\mathrm{PB}$ and reinitiate translation. Interactions between ARE-binding proteins have long been thought to determine the fate of ARE-containing transcripts. It is likely that this occurs, in part, by regulating the subcellular localization of these mRNAs. The discovery that $\mathrm{PB}$ assembly is linked to the availability of the executioner is an important advance in our understanding of the relationship between mRNA translation and decay. Like all important discoveries, the findings of Franks and Lykke-Andersen (2007) raise as many questions as they answer. If TTP/BRF proteins recruit PB components to individual mRNAs, how do these mRNAs join together to form a microscopically visible $\mathrm{PB}$ ? Can TTP/BRFassociated transcripts join an exisiting $\mathrm{PB}$ ? If so, how does the mRNP complex move to the PB? Is the composition of PBs assembled under conditions of excess versus limiting mRNA decay capacity different? 
Is the assembly of PBs regulated by protein modifications (e.g., kinases, phosphatases, methylases, etc.)? Are subcompartments within $\mathrm{PBs}$ that store silenced mRNAs distinct from subcompartments that degrade their doomed brethren? The answers to these questions will be essential to further our understanding of the life and death of RNA.

\section{Acknowledgments}

This work was supported by the National Institutes of Health grants AI33600, AI50167, and AI65858.

\section{References}

Anderson, P. and Kedersha, N. 2006. RNA granules. J. Cell Biol. 172: $803-808$.

Bakheet, T., Williams, B.R., and Khabar, K.S. 2006. ARED 3.0: The large and diverse AU-rich transcriptome. Nucleic Acids Res. 34: D111-D114.

Barreau, C., Paillard, L., and Osborne, H.B. 2005. AU-rich elements and associated factors: Are there unifying principles? Nucleic Acids Res. 33: 7138-7150.

Bashkirov, V.I., Scherthan, H., Solinger, J.A., Buerstedde, J.M., and Heyer, W.D. 1997. A mouse cytoplasmic exoribonuclease (mXRN1p) with preference for G4 tetraplex substrates. J. Cell Biol. 136: 761-773.

Beelman, C.A. and Parker, R. 1995. Degradation of mRNA in eukaryotes. Cell 81: 179-183.

Bhattacharyya, S.N., Habermacher, R., Martine, U., Closs, E.I., and Filipowicz, W. 2006. Relief of microRNA-mediated translational repression in human cells subjected to stress. Cell 125: 1111-1124.

Brengues, M., Teixeira, D., and Parker, R. 2005. Movement of eukaryotic mRNAs between polysomes and cytoplasmic processing bodies. Science 310: 486-489.

Caput, D., Beutler, B., Hartog, K., Thayer, R., Brown-Shimer, S., and Cerami, A. 1986. Identification of a common nucleotide sequence in the $3^{\prime}$-untranslated region of mRNA molecules specifying inflammatory mediators. Proc. Nat1. Acad. Sci. 83: 1670-1674.

Carballo, E., Lai, W.S., and Blackshear, P.J. 1998. Feedback inhibition of macrophage tumor necrosis factor- $\alpha$ production by tristetraprolin. Science 281: 1001-1005.

Chen, C.Y., Gherzi, R., Ong, S.E., Chan, E.L., Raijmakers, R., Pruijn, G.J., Stoecklin, G., Moroni, C., Mann, M., and Karin, M. 2001. AU binding proteins recruit the exosome to degrade ARE-containing mRNAs. Cell 107: 451-464.

Chu, C.Y. and Rana, T.M. 2006. Translation repression in human cells by microRNA-induced gene silencing requires RCK/p54. PLoS Biol. 4: e210.

Coller, J. and Parker, R. 2005. General translational repression by activators of mRNA decapping. Cell 122: 875-886.

Cougot, N., Babajko, S., and Seraphin, B. 2004. Cytoplasmic foci are sites of mRNA decay in human cells. J. Cell Biol. 165: $31-40$.

Eulalio, A., Behm-Ansmant, I., and Izaurralde, E. 2007. P bodies: At the crossroads of post-transcriptional pathways. Nat. Rev. Mol. Cell Biol. 8: 9-22.

Franks, T.M. and Lykke-Andersen, J. 2007. TTP and BRF proteins nucleate processing body formation to silence mRNAs with AU-rich elements. Genes \& Dev. (this issue).

Gao, M., Wilusz, C.J., Peltz, S., and Wilusz, J. 2001. A novel
mRNA-decapping activity in HeLa cytoplasmic extracts is regulated by AU-rich elements. EMBO J. 20: 1134-1143.

Garneau, N.L., Wilusz, J., and Wilusz, C.J. 2007. The highways and byways of mRNA decay. Nat. Rev. Mol. Cell Biol. 8: 113-126.

Graham, A.C., Kiss, D.L., and Andrulis, E.D. 2006. Differential distribution of exosome subunits at the nuclear lamina and in cytoplasmic foci. Mol. Biol. Cell 17: 1399-1409.

Kedersha, N., Stoecklin, G., Ayodele, M., Yacono, P., LykkeAndersen, J., Fitzler, M., Scheuner, D., Kaufman, R., Golan, D.E., and Anderson, P. 2005. Stress granules and processing bodies are dynamically linked sites of mRNP remodeling. J. Cell Biol. 169: 871-884.

Lai, W.S., Carballo, E., Strum, J.R., Kennington, E.A., Phillips, R.S., and Blackshear, P.J. 1999. Evidence that tristetraprolin binds to AU-rich elements and promotes the deadenylation and destabilization of tumor necrosis factor $\alpha$ mRNA. Mol. Cell. Biol. 19: 4311-4323.

Lai, W.S., Carballo, E., Thorn, J.M., Kennington, E.A., and Blackshear, P.J. 2000. Interactions of $\mathrm{CCCH}$ zinc finger proteins with mRNA. Binding of tristetraprolin-related zinc finger proteins to AU-rich elements and destabilization of mRNA. J. Biol. Chem. 275: 17827-17837.

Lai, W.S., Kennington, E.A., and Blackshear, P.J. 2003. Tristetraprolin and its family members can promote the cell-free deadenylation of AU-rich element-containing mRNAs by poly(A) ribonuclease. Mol. Cell. Biol. 23: 3798-3812.

Liu, J., Valencia-Sanchez, M.A., Hannon, G.J., and Parker, R. 2005. MicroRNA-dependent localization of targeted mRNAs to mammalian P-bodies. Nat. Cell Biol. 7: 719-723.

Lykke-Andersen, J. and Wagner, E. 2005. Recruitment and activation of mRNA decay enzymes by two ARE-mediated decay activation domains in the proteins TTP and BRF-1. Genes \& Dev. 19: 351-361.

Mukherjee, D., Gao, M., O'Connor, J.P., Raijmakers, R., Pruijn, G., Lutz, C.S., and Wilusz, J. 2002. The mammalian exosome mediates the efficient degradation of mRNAs that contain AU-rich elements. EMBO T. 21: 165-174.

Pauley, K.M., Eystathioy, T., Jakymiw, A., Hamel, J.C., Fritzler, M.J., and Chan, E.K. 2006. Formation of GW bodies is a consequence of microRNA genesis. EMBO Rep. 7: 904-910.

Piecyk, M., Wax, S., Beck, A.R., Kedersha, N., Gupta, M., Maritim, B., Chen, S., Gueydan, C., Kruys, V., Streuli, M., et al. 2000. TIA-1 is a translational silencer that selectively regulates the expression of TNF- $\alpha$. EMBO J. 19: 4154-4163.

Pillai, R.S., Bhattacharyya, S.N., Artus, C.G., Zoller, T., Cougot, N., Basyuk, E., Bertrand, E., and Filipowicz, W. 2005. Inhibition of translational initiation by Let-7 MicroRNA in human cells. Science 309: 1573-1576.

Pillai, R.S., Bhattacharyya, S.N., and Filipowicz, W. 2006. Repression of protein synthesis by miRNAs: How many mechanisms? Trends Cell Biol. [Epub December 29, 2006; DOI:10.1016/j.tcb.2006.12.007]

Schwartz, D.C. and Parker, R. 1999. Mutations in translation initiation factors lead to increased rates of deadenylation and decapping of mRNAs in Saccharomyces cerevisiae. Mol. Cell Biol. 19: 5247-5256.

Shaw, G. and Kamen, R. 1986. A conserved AU sequence from the $3^{\prime}$ untranslated region of GM-CSF mRNA mediates selective mRNA degradation. Cell 46: 659-667.

Shen, V. and Kiledjian, M. 2006. A view to a kill: Structure of the RNA exosome. Cell 127: 1093-1095.

Sheth, U. and Parker, R. 2003. Decapping and decay of messenger RNA occur in cytoplasmic processing bodies. Science 300: 805-808.

Spector, D.L. 2006. Snapshot: Cellular bodies. Cell 127: 1071.e 11071.e 2. 
Stoecklin, G. and Anderson, P. 2006. Posttranscriptional mechanisms regulating the inflammatory response. $A d v$. Immunol. 89: 1-37.

Stoecklin, G., Colombi, M., Raineri, I., Leuenberger, S., Mallaun, M., Schmidlin, M., Gross, B., Lu, M., Kitamura, T., and Moroni, C. 2002. Functional cloning of BRF1, a regulator of ARE-dependent mRNA turnover. EMBO I. 21: 4709-4718.

Stoecklin, G., Mayo, T., and Anderson, P. 2006. ARE-mRNA degradation requires the 5 '-3' decay pathway. EMBO Rep. 7: 72-77. 


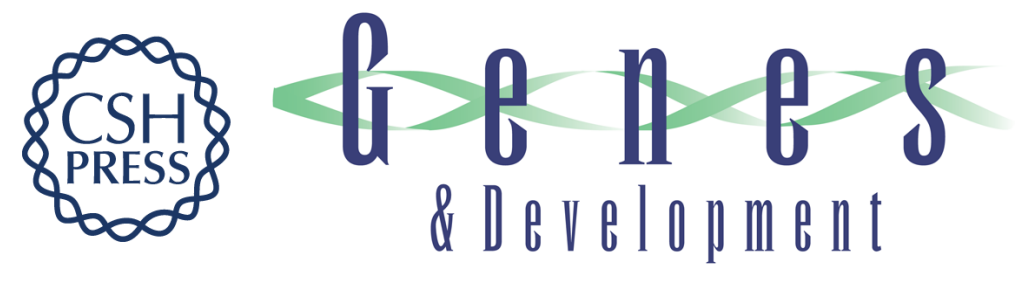

\section{In a tight spot: ARE-mRNAs at processing bodies}

Georg Stoecklin and Paul Anderson

Genes Dev. 2007, 21:

Access the most recent version at doi:10.1101/gad.1538807

Related Content TTP and BRF proteins nucleate processing body formation to silence mRNAs with AU-rich elements

Tobias M. Franks and Jens Lykke-Andersen

Genes Dev. March , 2007 21: 719-735

References This article cites 33 articles, 19 of which can be accessed free at: http://genesdev.cshlp.org/content/21/6/627.full.html\#ref-list-1

Articles cited in:

http://genesdev.cshlp.org/content/21/6/627.full.html\#related-urls

\section{License}

Email Alerting Receive free email alerts when new articles cite this article - sign up in the box at the top Service right corner of the article or click here.

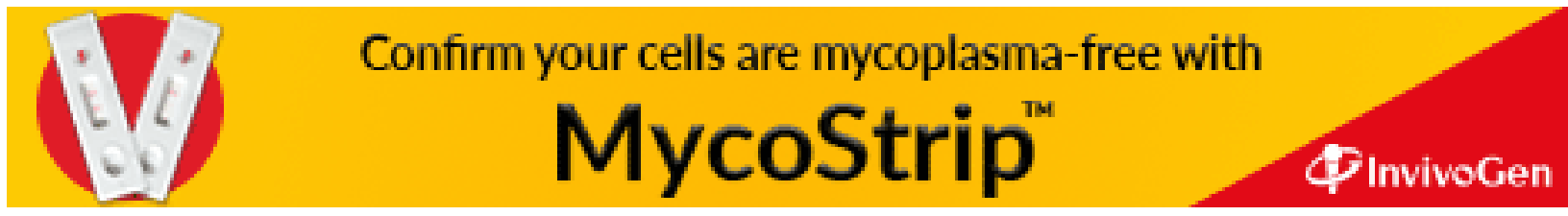

